\title{
SUSCEPTIBILIDAD A LA CONTAMINACIÓN SALINA DEL ACUÍFERO CONFINADO COSTERO DEL EJE BANANERO DE URABÁ CON TÉCNICAS HIDROGEOQUÍMICAS E ISOTÓPICAS, ANTIOQUIA, COLOMBIA
}

Vanessa Paredes (2010)

Este proyecto abarca un área de estudio de 8 $916 \mathrm{~km}^{2}$, está localizado en la zona noroccidental del Departamento de Antioquia, Colombia conocida como el Golfo de Urabá. Geológicamente la zona de interés se encuentra constituida por rocas sedimentarias terciarias (T1 y T2) y depósitos aluviales (Cuaternario). Las unidades hidrogeológicas de mejor potencial para el aprovechamiento de aguas subterráneas lo constituyen la unidad T2 (acuífero confinado) y los depósitos cuaternarios. La precipitación promedio de esta área es $2600 \mathrm{~mm} / a$ ño a $3600 \mathrm{~mm} / \mathrm{año}$. El objetivo de este estudio consistió en determinar la susceptibilidad a la contaminación salina del acuífero costero del eje bananero de Urabá, con la utilización de hidrogeoquímica e información geológica, geofísica, hidrogeoquímica e hidráulica para mejorar modelo hidrogeológico conceptual existente y realizar una caracterización hidrogeoquímica para evaluar los procesos de salinidad en el acuífero confinado.

La metodología utilizada para el desarrollo de esta investigación, fue la integración de la información geológica, geofísica e hidrogeológica para validar las características hidráulicas del acuífero, su geometría y funcionamiento para actualizar el modelo hidrogeológico conceptual; y a partir de allí, con el uso de herramientas complementarias determinar e identificar procesos que pueden afectar las características físicoquímicas naturales del agua subterránea.

Con los resultados obtenidos, se evidencia que los procesos de salinización presentes en el acuífero costero del Eje Bananero de Urabá podrían estar ligados a la interacción agua - roca, a mezclas con aguas que se salinizaron como resultado de procesos de transgresión-regresión antiguos en la zona de estudio. Las técnicas hidrogeoquímicas constituyen una herramienta complementaria a la hidrogeología dado que permiten responder los interrogantes que se presentan en sistemas complejos, como es el caso de los acuíferos costeros, donde la salinidad normalmente asociada a procesos de intrusión salina, puede obedecer también a la conjunción con otros aspectos hidroclimatológicos e hidrodinámicos. 